\title{
Alcohol Abuse Practices Among Residents of Busia Town, in Kenya
}

\author{
Brian Barasa Masaba \\ School of Nursing, Masinde Muliro University of Science and Technology, Nairobi, Kenya
}

\section{Email address:}

masababrian6@gmail.com

\section{To cite this article:}

Brian Barasa Masaba. Alcohol Abuse Practices Among Residents of Busia Town, in Kenya. American Journal of Health Research. Vol. 5, No. 1, 2017, pp. 11-18. doi: 10.11648/j.ajhr.20170501.13

Received: January 8, 2017; Accepted: January 16, 2017; Published: February 23, 2017

\begin{abstract}
Alcohol abuse is a major public health issue that has no social economic, ethnic, educational or geographical boundaries. It is a leading cause of morbidity, mortality and loss of productivity. (Tamara, et al, 2011). Alcohol use is associated with many public health problems including traffic crashes, violence, sexual assaults, and sexually transmitted disease, (Savola, et al, 2009). Numerous studies have shown that rates of alcohol use, and alcohol related problem increase with increasing alcohol availability Babor, et al, (2010). One venue where alcohol is readily available is community festivals, and annual celebration held in many communities across the United States, Wagenaar, et al, (2011). The aim of the study was to find out the alcohol abuse practices among residents of Busia town in Kenya. The study utilized a cross-sectional study design. It used both qualitative and quantitative methods in data collection where 421 Busia town residents' participated. Simple random, purposive and snowball non probability samplings were used to select participants. Exploratory and thematic content analyses were done. The study findings revealed that the age group that actively abused alcohol ranged from 22 years and above at $48 \%$. The most active was (22-27) and peer pressure and family history of alcoholism being most leading causative factors with $80 \%$ of the respondents. Alcoholism poses danger to individuals, families and the community as a whole. Health education was one of the major recommendations the researcher made. This will help the affected people to learn about the dangers of alcoholism and to undertake voluntary changes in their behavior. The health education may be either one to one or in groups or through mass media with an aim of reaching a large target group
\end{abstract}

Keywords: Daly- Disability-Adjusted Life Years, Alcohol Beverages, Chang'aa

\section{Introduction}

The World Health Organization (WHO) estimates that there are about 2 billion (33\%) people worldwide who consume alcoholic beverages and 76.3 million with diagnosable alcohol use disorders (WHO, 2009) making alcohol the most widely used and abused substance world over (Basangwa et al., 2011). Alcohol use has serious health and social effects making its prevention and control a public health priority. According to WHO (2002, 2004), alcohol causes 1.8 million deaths $(3.2 \%$ of total) one third $(600,000)$ of which result from unintentional injuries. It also causes a loss of 58.3 million (4\% of total) of Disability-Adjusted Life Years (DALY) of which $40 \%$ are due to neuro-psychiatric conditions. In Australia alcohol intoxication is responsible for $30 \%$ of road accidents, $44 \%$ of fire injuries, $34 \%$ of falls and drowning, $16 \%$ of child abuse cases, $12 \%$ of suicides, $10 \%$ of industrial accidents and $67 \%$ of the years of life lost from drinking (Government of South Australia, 2010).

In Africa the trend of alcohol consumption among young people has been documented to be skyrocketing upwards for example Nigeria's is ranked first among thirty countries with highest per capita consumption of alcohol globally (World Health Organisation, 2009). These rankings fail to account for the unrecorded production and consumption of alcohol (Jernigan \&Obot, 2006). The 2009 report did not indicate a decline in consumption but rather revealed that Nigeria consumed 10.57litres per head of the population (Toroyan, 2009). This corroborates Gureje et al. (2007) findings that 'heavy episodic drinking, rather than moderate drinking is 
common among users of alcohol in Nigeria' and that alcohol is the most commonly used drug among Nigerians

Alcohol is the most commonly abused substance in the country and poses the greatest harm to Kenyans as evidenced by the numerous calamities associated with excessive consumption and adulteration of illicit brews. According to KEMRI, alcohol abuse affects $70 \%$ of families in Kenya. There are an estimated two million addicts, ninety percent [90\%] of who are addicted to alcohol (KEMRI, 2009). Among the different types of alcoholic drinks, traditional liquor is the most easily accessible type of alcohol followed by wines and spirits and lastly chang'aa. In general, $30 \%$ of Kenyans aged 15-65 have ever consumed alcohol in their life; $13.3 \%$ of Kenyans currently consume alcohol totaling to at least 4 million people. Traditional liquor is still more likely to have been consumed by rural children than urban children. More children in rural areas are likely to have ever consumed chang'aa than those in urban areas (NACADA, 2012). Currently no research has been done in Busia town on the topic of study however from observation; alcohol consumption is high and widely practiced over all ages. This study therefore intends to find out the alcohol practices in Busia town.

\section{Materials and Methods}

\subsection{Study Design, Area and Population}

This was a cross sectional study design. It was carried out in Busia town. The study population comprised of dwellers aged 18 to 60 years, in the above town. Both men and women were given an equal chance of participation.

\subsection{Sample Size}

The sample size formula of Cochran (1977) was used to calculate the sample size as follows:

Sample size $=\mathrm{n}$

$$
\left[\frac{1+n}{\text { population }}\right]
$$

In which $\mathrm{n}=\left[\frac{Z^{2} \times(P) \times(1-P)}{d^{2}}\right]$

Where: $\mathrm{N}$ is the desired sampling size from the population. $\mathrm{q}=1-\mathrm{P}$ where $\mathrm{P}$ is the expected proportion of accessible population.

$\mathrm{Z}$ is the standard proportion accessible population which is taken to be 1.96

P Expected proportion of accessible population taken to be 0.50

$\mathrm{d}$ is the degree of accuracy or tolerable error taken to be 0.05

Calculation

Sample size $=\left[\frac{1.96^{2} \times 0.50 \times(1-0.50)}{0.05^{2}}\right]$

$\mathrm{n}=384.16$
The whole total population of Busia town is 95,875 according to 2009 census.

Where the population size is 95,875 then the following formula was used as per Cochrane's guide,

$\mathrm{S}=\mathrm{n} /[1+(\mathrm{n} /$ population $)$

$\mathrm{S}=384.16 /[1+(384.16 / 95,875]$

$\mathrm{S}=384.16 /[1+0.004]$

$\mathrm{S}=384.16 /[1.004]$

$\mathrm{S}=382.6$

$\mathrm{S}=382.6=100 \%$

Final sample size $=10 \%$ of sample +382.6

$$
\left[\frac{110}{100} \times 382.6=420.86\right]
$$

Final sample size $=421$

\subsection{Sampling Procedure}

Simple random probability, purposive and snowball nonprobability sampling methods were utilized. In this study, purposive sampling was utilized to get those specifically taking local alcohol and getting the targeted sample size of both men and women participants. Snowball used when the initially selected participants by random sampling led the researcher to the next alcohol user. Simple random sampling helped the researcher to randomly select Busia town that the research was to be carried out from, and selecting respondents by subjecting them to choose play cards marked yes and no.

\subsection{Criteria of Inclusion}

Busia town residents who consented to take part in the study and they were 18 to 60 years in age. Both men and women were given an equal chance to participate in the study.

\subsection{Study Tools}

The tool used for quantitative data collection was a structured interviewer administered questionnaire. The questionnaire was adapted from Asantegs. (2007). Assessment of the alcohol consumption trends in the costal region of jauben ethopia.

\subsection{Selection and Training of Enumerators}

Purposive and snowball non probability sampling was used to select fifteen and five BscN on internship program in Kisumu referral hospital and Kakamega county referral hospital respectively as enumerators. The enumerators were trained prior to data collection.

\subsection{Pre-testing of Research Tools}

The questionnaire was corrected after pilot study that was done in Kisii town residents.

\subsection{Data Collection}

Data collection was done using both quantitative and 
qualitative methods. They included cross-sectional survey.

\subsection{Data Analysis}

Exploratory data analysis was used to summarize quantitative data. This was done to summarize data in terms of frequencies, percentages and proportions. For qualitative data analysis, the following steps were followed: reception of cassette and tape recorders, data transcription, data organization, open, axial and selective coding, and evaluation of information selected.

\subsection{Ethical Considerations}

Ethical approval from Masinde Muliro University Ethics and Research Committee was sorted. The study participants were requested to give an informed consent of the study. To ensure confidentiality of individual clients' information, unique identifiers for study participants were used. The participants were also guaranteed of autonomy and were free to withdraw from participation.

\section{Results}

The socio-demographic information of the study participants was analyzed and their responses on the major factors influencing them to take alcohol categorized into the following themes; family influence, genetic factors, peer pressure, illiteracy, unemployment, also analyzed was frequently abused drugs and effects of alcoholism as reported by the study participants.

\subsection{Socio-demographic Information}

\subsubsection{Age}

The study findings revealed that the age group that actively abused alcohol ranged from 22 years and above at $48 \%$. The most active was $(22-27)$ at $48 \%$. This finding concurred well with a study done by NACADA, (2006) which revealed that the age group that mostly abused alcohol and other substances of abuse was between 15-40 years.

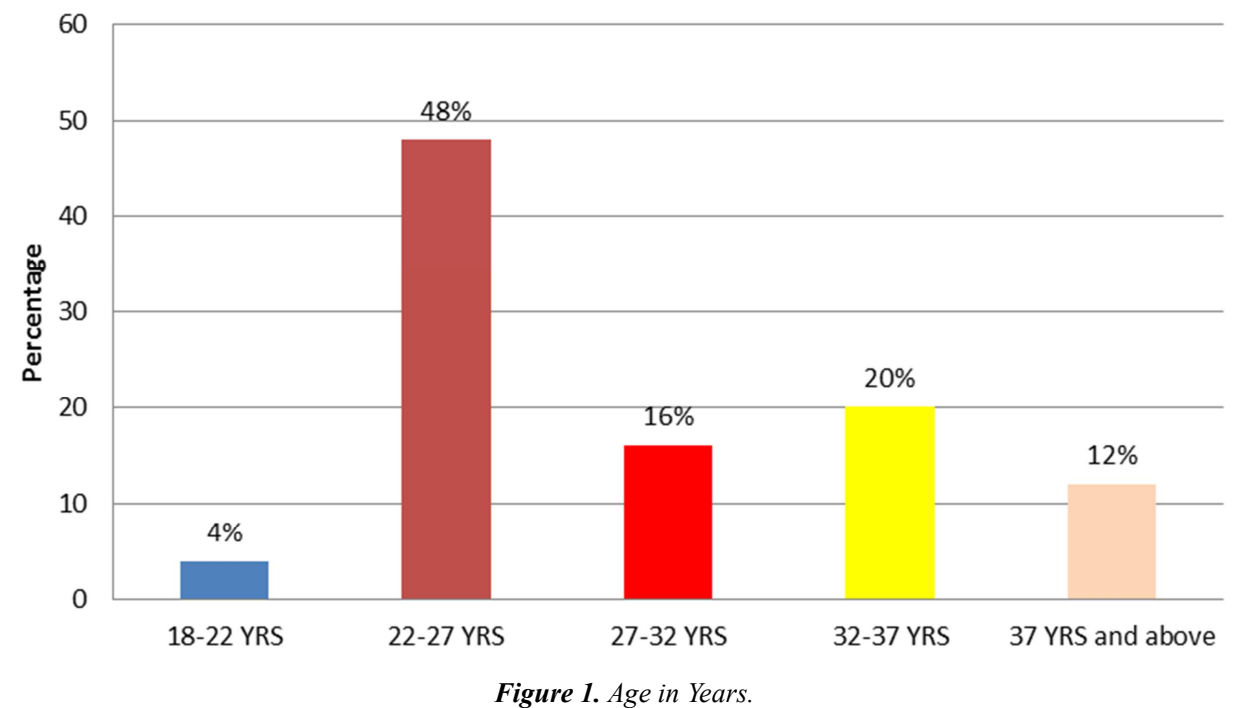

It is evident from the findings presented on the bar graph above that the age group that actively abused alcohol ranged from 22 years and above, at $48 \%$ while the least age was between $18-22$ years at $4 \%$.

\subsubsection{Sex}

According to the study findings, it was clear that the highly affected gender were males at $88 \%$ compared to $12 \%$ females. These results concurred with another study done by Shaw (2009). Digit (2006) found that 3\% of the population mostly men, in their late teens or twenties are responsible for $30 \%$ of all alcohol consumption in Scotland. A study done by Kimani, J (2006) indicated much consumption of alcohol and other substances of abuse were much higher for males than females.

Another study done by (Wallace et al 2003) revealed that alcohol consumption is higher in both females and males during the age 21-25 years. Where a study done by, Shaw, (2009) in the United Kingdom, showed that the ratio of male to female has been 5: 1. Recently, alcohol problem has increased substantially and disproportionally amongst women, Shaw, (2009).

Another study done by NACADA, (2006) revealed that both males and females engage in drug and substance abuse, however, it also indicated that a higher proportion of females than male consumed alcohol at 55.7\%. The study further indicated that more males than females engaged in using all types of drugs and substance. These results are similar to those found in the previous survey NACADA, (2004) that revealed that illicit drugs are consumed by both male and female.

\subsubsection{Marital Status}

The study findings revealed that majority of the respondents $40 \%$ were divorced/separated compared to single people at $4 \%$. This concurred with a study done by Deas, $\mathrm{P}$, (2008), that stated that $71 \%$ of individuals, who were divorced or separated and homeless abused alcohol and other drugs. Another study done by Kiipatrick, et, al, (2007) also stressful lifestyle increased the risk of developing alcoholism and other drugs and substance abuse. 


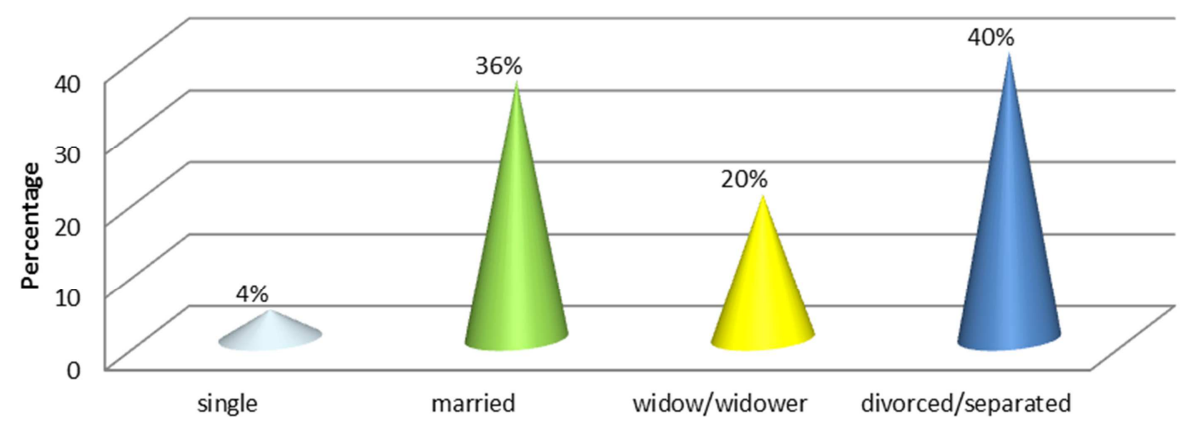

Figure 2. Marital Status.

The table above shows that divorced/separated individuals were most affected by alcoholic problems at $40 \%$ compared to single people at $4 \%$.

\subsubsection{Religion}

Religion is an important factor in prevention of alcoholism and drug abuse. The study revealed that non-believers. Consumed more alcohol at $48 \%$ compared to believers. The Muslims were at $12 \%$ while Christians were at $20 \%$. The study indicated that lack of religion is a risk factor for increased use. This study concurred with a study done by NACADA, (2004), which showed that there was a relationship between alcohol/substance abuse and religion faith, Islamic individual reported the least use, and Christians followed, while non-religious youth/individuals reported the most use, Kaguthi, (2004). The study conquered with other study done by Wallace, et al (2003). Which indicated that individuals who are more religious and uphold their religious values were less likely to use alcohol and other substance of abuse. However, the value and serious an individual attaches to religion is important.

\subsection{Factors Contributing to Alcoholism}

\subsubsection{Family Influence}

The study revealed that $80 \%$ of the respondents had family history of alcoholism. The study further revealed that $18 \%$ of the alcoholic were due to parental influence. The study also showed that alcoholism is related to some degree of mental illness. $4 \%$ of alcoholics had family history of mental illness. This result concurred with a study done by Latchman, (2008) which showed that alcoholism appear to run in families. It also stated some excessive drinkers have a family history of excessive drinking.

According to (Reinherz, et al 2000), families can protect an individual against alcohol and other drugs and substance of abuse such as, family structure, that is the size of the family and whether the child lives with the mother, father, or both parents.

Consumption of alcohol is regarded as a regular time by some members of the society. Some parents take their children along to bars and restaurants where they stay out till late in the night, allowing their children especially teens to visit alcohol selling outlets and drink alcohol in their presence. The parents unknowingly create an impression or belief that it is "cool" to drink alcohol. This impression contributes to the increasing number of underage drinkers, Gakunju. R, (2000).

A study done by, Mahugu. M, (2011) revealed that the family is also a transmitter of cultural attitude. Drinking may be engraved into the social life of the family because the circle of friends hat they relate with and their pattern of entertaining. Parental model are instrumental in shaping early attitude and behavior with regard to teenage alcohol abuse.

Another similar study done by Hawker, (1978) reported that the children tend to follow their parents drinking patterns; boys especially tend to be encouraged to drink more than girls at an early age. However, it is not uncommon to find people who are abstainers, although their parents drink heavily (Jahoda, et al 1972).

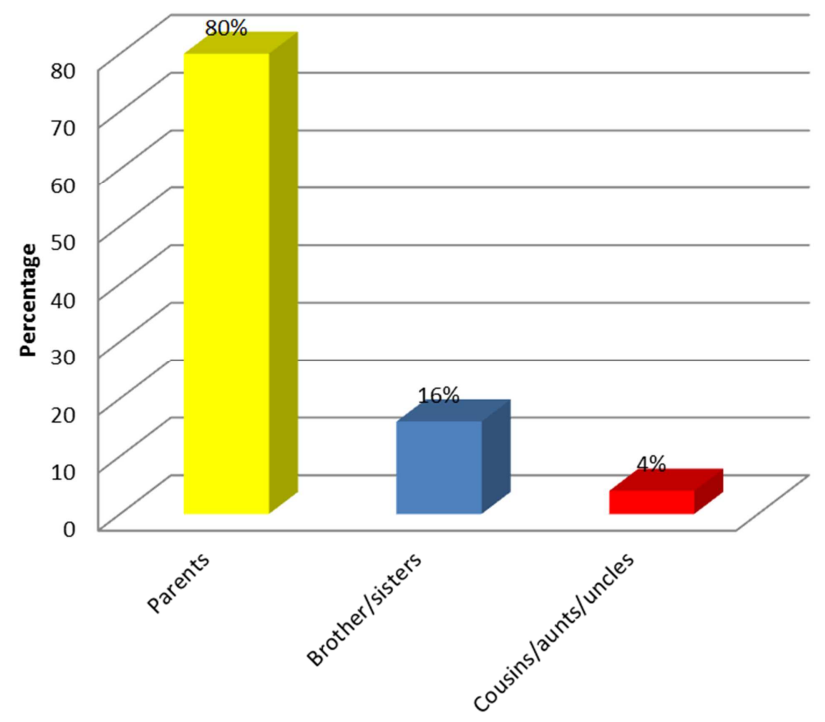

Figure 3. Family history of alcoholism.

$80 \%$ of the respondents had family history of alcoholism in the family.

\subsubsection{Genetic Factors}

The study revealed that the alcoholism tends to run in families. $80 \%$ parents of alcoholics, $16 \%$ brothers and sisters, $4 \%$ cousins, aunties and uncles were alcoholics.

This was in agreement with a study done by Latchman, (2008) that stated that alcoholism appears to run in families. 
Some excessive drinkers have a family to history of excessive drinking. These finding apply particularly to men, the evidence about women is less certain, (Latachman, 2008).

The study by NACADA, (2004) observed that the use of alcohol, bhang and miraa has indigenous roots and that the three substances have been widely used in the indigenous society. There however exists no evidence that substances abuse has been part of the indigenous heritage, indeed the indigenous society for most part regards drunkenness as a disgrace and a breakdown of the indigenous culture and introduction of foreign influences that have a variety of substances available on a scale, Kimani, J, (2006).

\subsubsection{Peer Pressure}

The study finding revealed that peer pressure played a major role as a predisposing factor to alcoholism at $80 \%$. This concurred with a survey done by NACADA which reported that alcohol is largely taken as the company of friends and in some cases alone or with relatives. Friends Company alone constituted to $63 \%$. Peer influence is implicit in a number of theories which suggests that individuals associated with peers who share social definition favorable to the performance of certain activities; the individual is likely to engage in alcohol and drug abusers just like other non-abusers would seek approval from peers, KIMANI, J, (2006). The survey also revealed that people close to the youths introduced them to substances abuse. Along this lines may include one's best friend, sister, brother, mother and father. In that order, most likely introduce one to alcohol (Kaguthi, 2004)

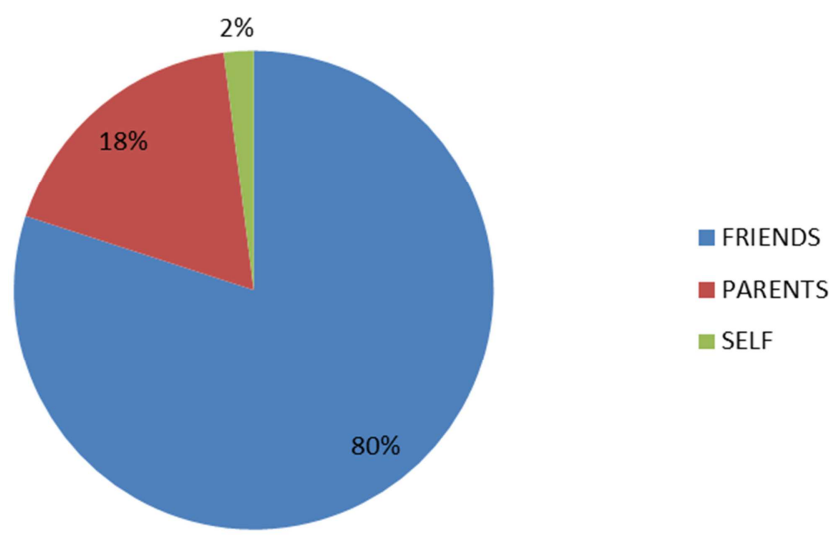

Figure 4. Who introduced you to drinking?

Study findings revealed that peer pressure played a major role as a predisposing factor to alcoholism at $80 \%$, parents $18 \%$ and $2 \%$ self as shown in the pie chart.

\subsubsection{Literacy}

According to the study findings, illiteracy contributed to alcoholism. Individuals with no formal education were at $48 \%$, those who reached primary school level contributed $40 \%$, secondary level $20 \%$ and tertiary level $28 \%$. This was supported by a study done by Becky, poor access to health are among major factors contributing to alcohol abuse (Becky, 2008).

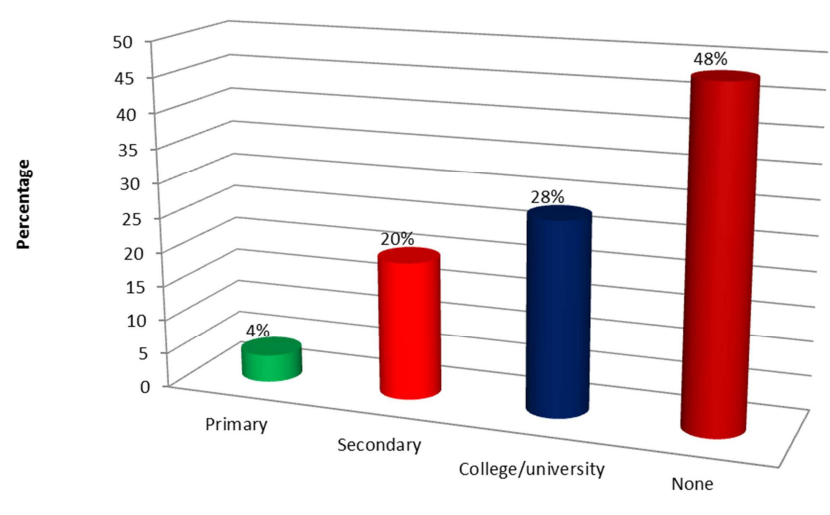

Figure 5. Level of education.

The study revealed that illiteracy contributed highly to alcoholism as shown above. Individuals with no education were at $48 \%$ compared to literate individuals, tertiary $28 \%$, secondary $20 \%$, and $4 \%$, at primary level.

\subsubsection{Unemployment}

It was evident from the study findings that unemployment is a leading factor to alcoholism, $68 \%$ of the respondents were unemployed. This concurred with a study done by Becky, (2008) that stated that economic stresses and unemployment is a contributing factor to alcohol abuse.

\subsubsection{History of Mental Illness}

According to the study finding, majority of the respondents $96 \%$ had no family history of mental illness. However $0.4 \%$ was parents, $2 \%$ brothers/sisters, and $0.6 \%$ cousins had mental disorders. This was in agreement with a research done by Deborah, D, (2008) which stated that psychiatrist disorder can concur with alcohol and other substances of abuse.

The presence of a psychiatric disorder can serve as a risk factor for the development of alcoholism and other drugs abuse disorders in both adolescent and adults. Another study done by Wagner et al (1996) found that depression, alcoholism and other drug use commonly coexisted among junior and seniors in high school and in attempted suicide cases.

\subsection{Frequently Abused Drugs}

The study finding revealed that the most frequently abused drinks was local brews at $84 \%$ compared to wine $2 \%$, spirit $2 \%$ and beer $12 \%$. This concurred with a study done by Kimani, J, (2006) which showed that high proportion of individuals have used alcohol compared to all other drugs and substances.

\subsection{Effects of Alcoholism}

Individuals feeling towards alcohol

The study finding indicated that alcohol does not add any value to individuals. $67 \%$ of the respondents were aware that alcohol did not add any value to their lives, 30\% were not sure, $32 \%$ of the respondents wished to quit drinking, $28 \%$ were not decided, while $40 \%$ saw no reason for quitting. $20 \%$ 
of the respondents were aware of where to seek help from, if they wished to quit alcohol, while $80 \%$ did not have any idea of where to go. $80 \%$ of the respondents wished to seek help to quit alcoholism and only $20 \%$ did not know whether they would wish to quit or not. The result also revealed that $80 \%$ of the respondents reported to have been criticized for drinking, while $20 \%$ had not been criticized.

A study done by William (2006) revealed that alcoholism physical effects, social effects and psychological effects. Increased intake of alcohol leads to dehydration, coordination problem, blurred vision, health and social problems. Alcoholism may have adverse effects on mental health that increases risk of suicides.

This was supported by a study done by Abbey et al (2006) that stated; when people are intoxicated, they frequently do things they normally would not do while sober, after ignoring legal, ethical social, moral or religious norms. While blurred vision, slurred speech, dehydration and coordination problems can be labeled as "short term effects of alcohol". Other health problems such as alcohol related heart problems, liver disease and cancer can be labeled as "long term effects of alcohol".

This concurred with another study done by Abbey et al (2006) that revealed that alcohol is associated with many public health problem including traffic crashes, violence, sexual harassment and sexually transmitted diseases.

This was supported by the study done by Russel, (2011) that revealed that addicted person no longer uphold work ethics and loses sense of responsibility. Being neat and well groomed takes a back seat; self esteem suffers, leading to actions that are uncharacteristic of the individual. Inappropriate work ethics leads to losing of jobs which in turn affect finance and wellbeing of their family. The alcoholic may also become abusive to their spouses and children either physically, emotionally or mentally. Alcoholism also leads to disassociation from friends and family members in an effort by the alcoholic to either hide their addiction or avoid critics from others.

\subsection{Control and Preventive Measures}

A study done by NACADA, (2006) reported that the government had realized the danger that drug and alcohol pose to the individual and the community and made commitment as follows:

- Ban on brewing and consumption of local brew.

- Enactment of the narcotic (control) psychotropic Act (1994).

- The government is obliged to prevent the selling of alcohol to underage drinkers and develop alcohol free environment for young people and other at risk group.

\subsubsection{Individual Level}

Control and prevention of alcohol may involve:

- Education and sensitization on dangers of alcoholism is given at individual level.

- Peer counseling groups should be promoted for the purpose of assisting the individuals who abuse alcohol.
- Counseling is an integral part in prevention of alcoholism, drugs and substance abuse the individuals affected

\subsubsection{Family Level}

The family has a great role to play in the control of alcoholism and substance abuse especially for the youth and other individuals. Parents should take the following steps:

- Knowing where your child is and what he/she is doing during unsupervised time especially after school, evening and school holidays.

- Keeping the children busy; engage them in after school activities. Studies show that teens who are involved in constructive, adult supervised activities are less likely to use drugs than those that are not supervised.

- Spending time together regularly and involved in your child's life. Get to know his or her friends

\section{Discussion}

The use of alcohol and other related drugs of abuse is closely associated with factors such as availability, peer pressure, social occasions, personal problem and curiosity. The most outstanding factor is peer pressure found at $80 \%$. Most alcoholics have peers who use or abuse alcohol. Kenyans have access to alcoholic's beverages at a very young age, although age at first drinking is set at 18 years. The drinking habits of the peers play a major role in initiating individuals into alcohol use or abuse. Anyone coming from an alcoholic family is more at risk of becoming an alcoholic. Therefore parents, caregivers, the media, other professionals and peers have a role to play in assisting young people to resist the use of alcohol and other substances of abuse.

\section{Conclusion}

According to the research findings, remedy should be sought to curb the continuity of alcoholism among the community members. The obvious ways are through Health Education, Guiding and counseling at individual level, family level and community level. From the research findings it is evident that alcoholism is a problem that requires proper attention, as it cuts across physical health, mental health, social health, financial relationship and occupational responsibilities. Therefore, each and every member of the society has a responsibility to be involved in the fight against alcoholism. It was thus found out that the best management of alcoholism was through Health Education, guidance and counseling. This should be accurate and comprehensive in order to facilitate reduction of alcohol consumption in the community. Finally, enforcement of laws, regulation and standards need to be strengthened to minimize accessibility, affordability and availability of alcohol and other substance of abuse. This needs to be addressed as a matter of priority. 


\section{Recommendations}

\section{Health education strategies}

Alcoholism poses danger to individuals, families and the community as a whole. Health education therefore would help the affected people to learn about the dangers of alcoholism and to undertake voluntary changes in their behavior. The health education may be either one to one or in groups or through mass media with an aim of reaching a large target group.

Individual level

- Education and sensitization on dangers of alcoholism is given at individual level.

- Peer counseling groups should be promoted for the purpose of assisting the individuals who abuse alcohol.

- Counseling is an integral part in prevention of alcoholism, drugs and substance abuse. The individuals affected by alcoholism should thus be given psychological support, treatment and rehabilitation as need arises.

Family level

The family has a great role to play in the control of alcoholism and substance abuse especially for the youth and other individuals. Parents should take the following steps:

- Know where your child is and what he/she is doing during unsupervised time especially after school, evening and school holidays.

- Keep the children busy; engage them in after school activities. Studies show that teens who are involved in constructive, adult supervised activities are less likely to use drugs than those that are not supervised.

- Spend time together regularly and involved in your child's life. Get to know his or her friends (and their parents) by talking with them at your child's school programs or other activities. Stay in touch with the adult supervisors of your child and have them inform you of any changes in your child's behavior.

- Parents, guardians and persons in authority should lay down the rules and strive to enforce them. Set the limits with clear consequences for breaking them.

- Alcohol and drug abuse takes on a new face each time and parents should strive to be informed to safeguard their children from taking alcohol and other drugs.

\section{Community mobilization}

The community members should be sensitized on dangers of alcoholism, through chief'sbarazas and focused group discussions (FGD). The members of FGD's should be drawn from local/ community leaders, religious leaders, medical personnel, teachers, parents, students, managers of colleges, lectures and trainers, law enforcement authorities, rehabilitations officers, drug abusers and workers in the institution, social workers and community health workers. Through discussion, sensitization and education on brewing and consumption; local brews may be controlled. The community structural and social institutions should be involved in prevention campaigns. The community should utilize media coverage in the primary prevention of substance and alcohol abuse. The media should provide motivational speakers on topics and issues related to drugs, alcohol and substance abuse. The community should identify and 'eliminate' sources and channels of drugs and substance of abuse especially illicit brews.

School health

There is need to introduce alcohol, drug and substance abuse awareness and knowledge in the school syllabus.

- The youth should be sensitized on dangers of alcohol and drug abuse in schools.

- They should be taught life skills (skills that will improve their lives).

- Peer counseling groups should be promoted in schools and all other educational institutions.

- Youth should be involved in awareness program and prevention campaigns, through their respective schools.

- Enact specific laws to deal with drug issues in schools.

Government policies

Counseling and health education is an integral part in prevention of alcoholism, drugs and substance abuse. Counseling centers should be established in all health institutions to assist people who abuse alcohol and other substances in the country.

The provision of psychosocial support, treatment, and rehabilitations are paramount. Therefore funding support from the Government of Kenya may play a key role in strengthening alcohol abuse prevention, and rehabilitation.

The Government should strengthen the Alcoholic Drinks Act 2010. Strict law enforcement plays a key role in reducing alcoholism and substance abuse.

There should be increased access to treatment and rehabilitation promoted through free programs, for the general population and special programs for the disabled, prisoners and women.

There should be provision of grants for research including academic research which may enable generation of much information on alcohol, drug abuse in the country.

The relevant agency in collaboration with government agencies, relevant civil society groups, to include sport and leisure clubs, parents, teachers and counselors should provide trainings, sensitization and awareness programmers on alcohol drinks control for the community workers, social workers.

\section{References}

[1] Basangwa. (2010). Alcohol and substance and mental disorders.

[2] Chesang. (2013). drug abuse among the youth in Kenya. international journal of scientific and technology research.

[3] Chikere. (2011). prevalence and percevied health effect of alcohol use among male undewrgraduate students in Owerri,south -east Nigeria:Adescriptive cross sectional study.

[4] ford. (2013). alcohol use among college students. A comparison of athletes and non-athletes.

[5] Gureje. (2011). a descriptive epidemiology of substance use and substance use disorders in Nigeria during the early $21 \mathrm{st}$ century. Drug and alcohol dependence. 
[6] Jernigan. (n. d.). thirsting for the African for the African market. african journal of drug and alcohol studies, 57-70.

[7] Jernigan. (2009). thirsting for the African market. African journal of drug and alcohol studies.

[8] Kilpatrick. (2013). risk factors for adolescent substance abuse and dependence:Data from a national sample. journal of counsulting and clinical psychology, 19-30.

[9] Koriech. (2008). Alcohol and empire:ilict gin prohibition and control in colonial eastern Nigeria. African economic history, $111-134$.

[10] Martta. (2010). drug situation in Finland 2010. National report to the EMCDDA. During situation in Finland.

[11] Miller. (2009). costs of alcohol and drug abuse.

[12] NACADA. (2009). National campaign against drug abuse:Fact finding mission report on the extent of Alcohol and drug abuse in central province.

[13] NACADA. (2012). Role of school environment in alcohol and drug abuse among students. evidence from public secondary school students in Nairobi.

[14] NACADAAlcohol use in central province of Kenya. A Basline survey on Magnitude, C. a. (2011).

[15] Odejide. (2010). status of drug use/abuse in Africa:International journal of mental health and addiction.

[16] Otieno. (2012). improving adherence to ante-retroviral treatment for people with harmful alcohol use in Kariobangi, Kenya through participatory research and action. BMC Public health, pp. 677-684.

[17] Rintaugu. (2012). Determinants of Alcohol Consumption of University Student-Athletes: The Case of university Nairobi. Current Research Journal of Social Sciences, 354-361.
[18] Smart. (2008). alcohol and human health. oxford university press.

[19] Toroyan. (2009). global stus report on road safety. Geneva: world health organisation.

[20] WHO. (2009). Alcohol in developing societies summary. Geneva: world health organisation.

[21] WHO. (2009). Alcohol in developing societies:A Public health approach. Geneva.

[22] WHO. (2008). Alcohol in developing socities: a public health approach. Geneva.

[23] WHO. Global status report on alcohol. Geneva.

[24] WHO. (2011). Global status report on alcohol and health. Geneva: world health.

[25] WHO. (2011). Global status report:Alcohol policy. Geneva.

[26] WHO. (2011). Global stus report. Geneva.

[27] WHO. (2009). Towards a global strategy to reduce harmful use of alcohol-discussion paper for regional technical consultation on harmful use of alcohol. department of mental and substance abuse world health organisation.

[28] Wills. (2008). change and continuity in cultures of drinking in subsaharan Africa. journal of drug alcohol study, 1-15.

[29] Wills. (2009). coping dimensions. life stess and adolescent substance use:Alatent growth analysis. journal of abnormal psychology, 309-323.

[30] Asantegs. (2007). Assessment of the alcohol consumption trends in the costal region of jauben ethopia. 